\title{
Modelling the Variability of Skin Stiffener Debonding in Post-Cured Top-Hat Stiffened Panels
}

\author{
J.E. Yetman ${ }^{\mathrm{a}, *}$, A.J. Sobey ${ }^{\mathrm{a}}$, J.I.R. Blake ${ }^{\mathrm{a}}$, R.A. Shenoi ${ }^{\mathrm{a}}$ \\ ${ }^{a}$ Fluid Structure Interactions, University of Southampton, University Rd, Southampton \\ SO17 1BJ, England, UK
}

\begin{abstract}
Glass structures are often used in industries utilising large structural topologies. These structures are typically manufactured by post-curing subcomponents together, using a chopped strand mat layer at the interface. To predict failure of these joints requires an accurate assessment of the material and fracture properties. In this paper two industrially manufactured top-hat stiffened panels are tested to determine the fracture behaviour at the component level. This highlights that the variability seen in fracture properties at coupon level is less evident in structural component response. Then a previously developed set of material properties is used to accurately model the structural response, crack initiation and debonding of the panels under four point bend using Finite Element Analysis which gives final failure at $6.2 \mathrm{kN}$ and a $4.4 \%$ error compared to the experimental results which exhibits final failure at $5.94 \mathrm{kN}$. The specific fracture properties tested and $\mathrm{R}$ curve are shown to be critical in assessing crack initiation and propagation with considerable error, $14.5 \%$, provided by data assumed from the literature.
\end{abstract}

Keywords: Fracture, Material Characterisation, Delamination, GFRP

\section{Introduction}

The majority of composite components are made from E-glass as they provide a balance between performance and cost. This is especially the case for large structural applications found in industries such as marine and civil engineering. For large engineering structures composite joints between plates, stiffeners and other sub components are often post-cured due to the scale of the production process and typical interfaces contain a chopped strand mat (CSM) layer. Debonding of subcomponent parts is a common failure mode of these types of structures however the characterisation of these typical post-cured interfaces is not well understood.

\footnotetext{
${ }^{*}$ Corresponding author

Email address: J.E.Yetman@Soton.ac.uk (J.E. Yetman)
} 
Due to the severe consequences of delamination a number of authors investigate stiffener skin debonding of composite components. Yap [1], Wiggenraad et al. [2], Meeks et al. [3], Orifici et al. [4] and Suh [5], investigate impacted I and T stiffened panels experimentally and demonstrate modelling capability. Yap [1], Wiggenraad et al. [2] and Meeks et al. [3] show that delaminations present under the stiffener have a significant effect on the ultimate strength of the panel where Yap [1] investigates the critical modelling parameters affecting crack growth within the stiffener and plate. Wiggenraad et al. [2] demonstrates that the skin-stiffener interface was critical when considering damage resistance. Yetman et al. [6] investigates top-hat stiffened panels using FEA, demonstrating that the position of the damage within the panel has a substantial impact on the crack growth, exhibiting a difference in final crack length and failure mode of the panel. However, the focus in this literature is on co-cured joints that neglect the CSM layer which is present in stiffener-plate joints. For the first time Yetman et al. [7] provides a complete set of mechanical and fracture properties for co-cured and post-cured materials with an E-glass woven roving. The results show a large difference in the fracture properties to previous literature. However, no experiments have been documented on structural components, to see how these varying properties effect the failure at this scale and further analysis is required to determine how critical the modelling parameters are for accurate FEA.

Cohesive or interface elements, based on a Dugdale-Barenblatt Dugdale [8] type cohesive zone look to model the region between the interface plies. The interface is assumed to be attached by 'springs' which dissipate energy during microcracking and once this energy is equivalent to the fracture toughness then cracks form. This method combines a fracture mechanics and damage mechanics approach; cohesive elements use a strain softening constitutive model in the interface process zone ahead of the crack tip and relate displacement continuities with traction vector at the process zone to the fracture toughness and crack surface area. Many constitutive models have been proposed with the most common being a linear strain softening behaviour, but whether it is appropriate for post-cured joints is not known.

Turon et al. [9] suggested a method where the efficiency issues associated with cohesive element size can be overcome by artificially increasing the interface strength therefore decreasing the cohesive zone length and scale of elements required during analysis. The assessment of the cohesive interface strength for the cohesive element method is unclear in the literature and whilst it is shown to be less critical whilst modelling at the scale of the cohesive zone length by Alfano and Crisfield [10] it is critical to Turon's method for improving the efficiency whilst providing accurate results Turon et al. [9].

Experiments are performed on a top-hat stiffened beam manufactured to a typical industry quality under four point bend; the first set of experiments looking at post-cured components in fracture. The beam is post-cured to a plate with an interface chop strand mat layer typical of the marine industry. This is performed for two different components to determine how the variation in manufacture can be accounted for in the FEA models. Characterisation 
data from Yetman et al. [7] is applied in an FEA model and compared to a model generated from characterisation data from the literature. To ensure a computationally efficient model the sensitivity of the cohesive element to the interface strength values is determined using the experimental data determined from Yetman et al. [7] and the linear strain softening model is tested.

\section{Four Point Bend Tests on Top-Hat Sections}

Experiments are conducted using a four point bend test to establish the crack initiation and propagation through representative top-hat stiffened structures. To manufacture the specimens the plate is initially infused and in a second process the top-hat stiffener is cured onto the plate with an interface layer of chopped strand mat. The material considered is a Scott Bader Crystic Resin VE679-03PA with a balanced 600gsm E-glass, plain weave repeat motif, woven roving with a sizing specific to the vinylester infusion and typical of resin infused based builds. The chopped strand mat interface layers are $450 \mathrm{gsm}$ E-glass mats manufactured by Jushi for vinylester infusion; CSMEMC450. The resin is a preaccelerated, DCPD modified, vinylester resin, developed for use as an infusion resin and cured for $24 \mathrm{hrs}$ at $20^{\circ} \mathrm{C}$ followed by $16 \mathrm{hrs}$ at $40{ }^{\circ} \mathrm{C}$. A period of at least 10 days was given between manufacture and testing, at room temperature, as recommended by the manufacturer to ensure a full cure. They are manufactured by a professional composite manufacturing company, reflecting a typical industry quality manufacture. This resulted in a fibre volume fraction of 0.61 Yetman et al. [7] and a void content of $1.78 \%$ with a standard deviation of 2.14 taken over 42 images from 3 specimens.

Three samples were cut from the two stiffeners, stiffener A and B, and tested under a four point bend to assess the consistency of the manufacturing technique. A load is applied to the four point bend test configuration, as shown in figure 1, until the specimen reaches ultimate failure; either by full delamination or until loss of the structural integrity of the laminate or stiffener occurs. The four point bend load position is established with the lower rollers positioned under the inner edge of the flange. This configuration minimises the risk of fibre failure on the upper surface of the laminate compared to a three point bend configuration. Load deflection data was recorded and delamination initiation and growth was observed and marked visually and audibly using a DSLR camera. The roller positions and stiffener dimensions are shown in figure 1. The plate and stiffener webs woven roving is aligned with the stiffener direction, where the table of the stiffener contains an additional central glass-vinylester unidirectional ply, UE500. Further details of the material properties can be found in Yetman et al. [7]. The plate, stiffener webs and stiffener table are $7.5 \mathrm{~mm}$, $3.75 \mathrm{~mm}$ and $7.5 \mathrm{~mm}$ thick respectively.

The load deflection curves are shown in figure 2. The initial stiffness is shown to illustrate how it changes with increasing displacement. For both stiffeners the three curves show good repeatability in the experimental set-up, showing little variation between the specimens from the same stiffener or between stiffeners. 
Observations taken during loading of specimen A3 are described in table 1 and of specimen B3 in table 2 which are typical of the results for each stiffener.

For both samples cracking was audible at relatively low displacements and were frequent throughout loading as crack development was gradual and continuous. This initial audible crack is comparable to the change in stiffness present in the load displacement curve. Stiffener A and B experience similar failure mechanisms. Stiffener A demonstrates a greater degree of asymmetry, across the three samples, with crack propagation dominant in the right hand flange plate interface. A level of variation is expected due to the inherent variability in the chopped strand mat at the interface which will provide variation in the strength of the interface. However, due to the similarity of mechanisms for the three tests it is assumed that the asymmetry observed is representative of a geometric or infusion variation rather than interface variability caused by the chopped strand mat. To further illustrate the damage state of stiffener A the damage response of $\mathrm{A} 3$ at $35.6 \mathrm{~mm}$ is shown in figure 3 .

There is a $1 \%$ difference in the average stiffness between stiffener $\mathrm{A}$ and $\mathrm{B}$ and a coefficient of variation across all tests of $1.4 \%$ showing low variability. This gives good confidence in the manufacturing technique and supplier, but demonstrates a lower variation than that seen from test specimens created from the same panels in Yetman et al. [7].

\section{Finite Element Modelling}

The modelling methodology is implemented as described in Yetman et al. [6]. Cohesive elements are used with a linear degradation to model the crack interface and material failure is monitored by the Tsai-Wu failure criterion, which was previously validated for similar materials. The interface strengths for E-glass vinylester composites are taken from experimental data determined in Yetman et al. [7] for post-cured materials. The material properties determined experimentally are used to validate the material model and the cohesive element properties are optimised to account for the chopped strand mat interface and fibre bridging present behind the crack tip. The four point bend configuration is used to validate the model and assess the sensitivity of the material properties ascertained by coupon testing and those acquired from the literature.

\subsection{Post-Cured Mode I and II Coupons}

The Mode I, Double Cantilever Beam, DCB, and mode II, End Notch Failure, ENF, coupons from Yetman et al. [7] are simulated to assess the appropriate interface strength, cohesive zone length and establish Turon's interface parameters. Mode I and II samples are modelled representing a post-cured pre-cracked sample, $6 \mathrm{a} 2$ and $7 \mathrm{a} 6$ respectively. As averaged properties are used in future modelling these samples are chosen as the critical strain energy release rates which are closest to the average properties. The samples are modelled with a $5 \mathrm{~mm}$ width to improve the efficiency of the model and results are scaled experimentally. The DCB sample has a crack length of $34 \mathrm{~mm}$ and an average critical 
strain energy release rate of $1.39 \mathrm{~kJ} / \mathrm{m}^{2}$ compared to the average for the sample set of $1.15 \mathrm{~kJ} / \mathrm{m}^{2}$. The ENF sample has a crack length of $30 \mathrm{~mm}$ and a critical strain energy release rate of $1.56 \mathrm{~kJ} / \mathrm{m}^{2}$, compared to an average of the sample set of $1.59 \mathrm{~kJ} / \mathrm{m}^{2}$. Both models use the mechanical properties from experiments where the flexural modulus is $25.053 \mathrm{GPa}$. Initially a small mesh size is used which is assumed to be smaller than the cohesive zone length with a cohesive element size of $0.2 \mathrm{~mm}$ and shell element size of $1 \mathrm{~mm}$. The affect of the interface parameter, $\mathrm{M}$, is chosen and the cohesive zone length is measured to ascertain the interface parameter in Turon's relationship. The interface parameter is then verified for increasing cohesive zone size and therefore mesh size.

The results are compared to the experimental and analytical results for varying values of the interface strength for the DCB in figure 4 . The DCB test shows a significant $\mathrm{R}$ curve and therefore the peak load and crack propagation of the model are not accurate the experiment as the average critical strain energy release rate is used. However, the crack propagation of the analytical solution is well matched by the model giving confidence in the converged solution. Crack propagation is captured well by the mode I model for all interface strengths tested where interface strengths of $125 \mathrm{MPa}$ and larger are shown to provide a converged solution with a linear response until crack propagation is evident. As the interface strength reduces the response becomes less stiff prior to crack propagation and reduces the peak crack initiation load. It is noted by Alfano and Crisfield [10] that the variation of the maximum interfacial strength does not have a strong influence on the predicted properties but reducing the interface strength can aid convergence. Therefore, a minimum interface strength is selected, $125 \mathrm{MPa}$, that accurately models the crack propagation and stiffness. This selection provides a linear response until crack propagation occurs. At this interface strength the cohesive zone length is 0.82 which is measured from the model as the distance over which the cohesive through thickness traction reaches the interface strength. The interface parameter is therefore calculated as 0.445 . The interface strengths and cohesive zones are scaled with parameters shown in table 3 and the load deflection curves for each cohesive length are shown in figure 5. It is noted that increasing the cohesive zone lengths to $1.67 \mathrm{~mm}$ and $5.0 \mathrm{~mm}$ creates a slight deviation in the initial stiffness which is likely to be due to the convergence of the shell elements for this specific configuration. However, the peak load and crack propagation response are well modelled for both mesh sizes with a $5 \%$ increase in the peak load for the largest mesh size with all the key features represented.

The results are compared to the experimental and analytical results for varying values of the interface strength for the ENF samples in figure 6. It is shown that as the interface strength increases the load deflection response approaches the analytical solution which remains linear until the crack propagates. As the interface strength reduces the stiffness of the coupon reduces at lower loads and the peak load is reduced. The experimental results show a degree of nonlinearity indicating micro-cracking ahead of the crack tip and energy dissipation prior to crack propagation. The non-linearity is well represented by an interface strength of 50MPa however the peak load is under-estimated. To account for the 
energy dissipation prior to crack propagation the model is tested with a critical strain energy release rate of $1.71 \mathrm{~kJ} / \mathrm{m}^{2}$ representing $130 \%$ of the experimental measured energy and compared for a range of interface strengths. It is shown that an improved fit for the experimental data can be achieved by this method. However, without an assessment of the fit of reducing the interface strength on the quadratic stress criterion in comparison to the mixed mode curves, an interface strength of $150 \mathrm{MPa}$ is chosen which provides a good estimate in comparison to the analytical response. At this interface strength the cohesive zone length is $1.00 \mathrm{~mm}$ which is measured from the model as the distance over which the cohesive through thickness traction reaches the interface strength. The interface parameter is therefore calculated as 0.57 . The interface strengths and cohesive zones are scaled with parameters shown in table 3 and the load deflection curves for each cohesive length are shown in figure 7. Good agreement is shown for cohesive zone lengths of $1 \mathrm{~mm}$ and $1.67 \mathrm{~mm}$ with the initial stiffness, peak load and crack propagation well modelled compared to the analytical solution. The $5 \mathrm{~mm}$ cohesive zone model introduces a $1.7 \%$ error in the peak load but shows good agreement to the analytical solution.

Turon's method is therefore verified for this material for DCB and ENF samples with key parameters summarised in table 4 .

\subsection{Four Point Bending Test Comparison}

A quarter model of the top-hat four point bend configuration is created as shown in figure 8 . The shells are shown as being coincident at the flange plate interface and the offset is defined in the section definition. Symmetric boundary conditions are applied to the inner 2-3 plane and 1-3 plane. The upper and lower rollers are fully constrained with the exception of a displacement load applied to the lower roller up to $50 \mathrm{~mm}$ parallel to the vertical, ' 3 ', axis. The inner and outer rollers are positioned symmetrically about the center at $85 \mathrm{~mm}$ and $325 \mathrm{~mm}$ widths respectively.

The material properties are given in table 5 for the assumed properties taken from the literature and the experimentally determined results. The assumed properties are taken from associated data where available. The BenzeggaghKenane exponent Benzeggagh and Kenane [11] is calculated at 1.17 using the least squares fitting method through similar available data which gives an $R^{2}$ value of 0.9242 showing a good fit.

The experimental data is presented as determined and the non-critical material properties are assumed from similar data. The maximum shear stress observed is of the order of $10 \mathrm{MPa}$ which is within the initial linear region of the experimental results. Therefore the shear modulus is approximated to a linear stress-strain response with shear modulus of $7 \mathrm{GPa}$. Cohesive elements are used at the interface with a depth of $0.01 \mathrm{~mm}$.

The interface strengths are calculated by equation 1 as recommended by Turon et al. [9] where $l_{e}$ is the mesh size in the direction of crack propagation, $N_{e}$ is the number of elements in the cohesive zone, $\mathrm{M}$ is the interface parameter depending on the cohesive model which is normally close to unity, $E_{2}$ is the transverse modulus of orthotropic material and $G_{i c}$ is the critical strain energy 
release rate. The cohesive zone length is therefore given by $l_{c z}=N_{e} l_{e}$ and is set as the converged shell mesh size and the interface strength, $t_{o_{i}}$, can be calculated from equation 1 ,

$$
t_{o_{i}}=\sqrt{\frac{M E_{2} G_{i c_{i}}}{N_{e} l_{e}}}
$$

A mesh convergence study is conducted, using the experimental material properties shown in table 5 for decreasing shell element size. Turon's method is used to determine the interface strength, with 3 cohesive elements within a cohesive zone length which is equivalent to the shell element size; the cohesive viscosity parameter is set to $1 \mathrm{E}-5$. In this study material degradation is neglected. The load deflection curves for the full model are shown in figure 9 for decreasing shell element size. It is shown that the response converged for the initial stiffness and non-linearity between $25 \mathrm{~mm}-31 \mathrm{~mm}$ roller displacement for a mesh size of $3.3 \mathrm{~mm}$ or less. Good correlation is shown between the three mesh sizes and therefore cohesive zone sizes. There is a $5.5 \%$ variation between the peak loads using an element size of $5 \mathrm{~mm}$ and $2.5 \mathrm{~mm}$ showing the calculation of the interface parameter could be improved although it provides a reasonable estimate for an acceptably larger mesh size. For this study a mesh size of $2.5 \mathrm{~mm}$ is chosen which provides the most conservative response. Assessment of the mode mix shows the inner edge propagates under $86 \%$ mode II opening whereas the outer flange edge is mode I dominant with only $3 \%$ mode II.

A number of modelling parameters are compared in response to the load displacement curves as shown in figure 10. It is shown that the stiffness of the top-hat stiffened plate is underestimated with a $10 \%$ reduction compared to the experimental data. The measured lamina thickness is input into the model and it is assumed that there is a discrepancy between the measured coupon flexural modulus and the top-hat stiffened plate. The variation in flexural modulus is observed between the mode II and flexural testing and could be a result in variation in the manufacturing process as similar variation is commented on by Dharmawan et al. [12]. The initial non-linearity is captured reasonably well by the model where non-linearity occurs at a displacement of $14 \mathrm{~mm}$ but is not conservative as non-linearity is observed experimentally at approximately $6.8 \mathrm{~mm}$ for panel B and $9.0 \mathrm{~mm}$ for panel A. However failure is predicted using the crack initiation values at a load of $3.61 \mathrm{kN}$ with complete debonding of the top-hat stiffener. The crack propagation and ultimate failure is well modelled by the crack propagation strain energy release rates with final failure predicted by debonding at $6.2 \mathrm{kN}$ compared to the experimental value of $5.94 \mathrm{kN}$ which was due to material failure under the rollers. The model is limited as it fails to capture crack initiation and propagation at the web flange curve of the top-hat stiffener but provides a good approximation within its limitations.

The experimentally determined properties are compared to the assumed mechanical properties from the literature which are summarised in table 5 . Figure 10 shows that the initial linear phase is well captured by the assumed properties gathered from the literature however the crack initiation, propagation 
and failure provide a non-conservative result and the new properties provide a substantial improvement.

Crack length against roller displacement for the inner and outer flange edges are compared where crack initiation is determined when the stiffness of the cohesive element is degraded to $5 \%$ of the initial stiffness. Degradation of the cohesive elements begins at a deflection of $8.68 \mathrm{~mm}$ when the cohesive strength criterion is exceeded however, crack initiation is predicted on the inner and outer edge at a roller displacement of $12 \mathrm{~mm}$ using the crack initiation model. This corresponds well to the experimental results with audible cracks heard at 6.4 and $7.1 \mathrm{~mm}$ roller displacement. There is considerable scatter in the crack length data experimentally however, it is shown that crack initiated on the outer curve on one side of stiffener A earlier than predicted, which may have been caused by an imperfection at the joint, but the results for the other outer flange interfaces correlate well.

The shear stresses are assessed to determine the effect of non-linearities in the shear properties. The maximum shear stress is $13 \mathrm{MPa}$ observed in the flange area in the region of the crack tip and is therefore unlikely to be affected by nonlinearity in shear. Figure 11 shows the stresses in the fibre direction aligned with the lateral plies, parallel with the y direction at $47.5 \mathrm{~mm}$ roller displacement. At a roller displacement of $35 \mathrm{~mm}$ the stresses are approaching the failure stresses of the woven roving. The stress in the flange web curve is approaching the tensile stress of $444 \mathrm{MPa}$ however experimentally it is observed that mid-laminate cracks develop in this area relieving this tensile stress. Contact is not modelled between the roller and the plate and therefore failure in this area is not taken into account however in the experimental results it is assumed that accumulating damage under the rollers does not adversely affect the crack propagation or load-roller displacement response prior to failure.

In summary the method for modelling crack initiation and crack propagation for debonding of a top-hat stiffened plate is modelled with good agreement with the experimental results. Turon's method is used to artificially increase the cohesive zone length with reasonable agreement for increasing mesh size for the parameters identified, reducing the computational time and increasing the practicality of these techniques. The specific fracture properties as tested are shown to be critical in assessing crack initiation and propagation with considerable error provided by data assumed from the literature for this configuration. Further testing is required to understand these post-cured properties and their variability.

\section{Conclusions}

Two post-cured top-hat stiffened panels, manufactured by industry, are tested experimentally under four point bend. These tests highlight that the variability shown between specimens at the laminate scale are not present in the structural components. An FEA model is developed and shown to accurately predict the structural response, to within $4.4 \%$, including the crack initiation and propagation of a debonding stiffener using the experimentally determined material 
properties. The mode I and II interfaces strengths are calculated using Turon's method and verified for increasing mesh size and verified against the experimental results for specific configurations. It is shown that micro-cracking ahead of the crack tip is evident for mode II crack opening and the interface strength can be adjusted to improve the cohesive element model. The specific fracture properties and as tested $\mathrm{R}$ curve are shown to be critical in assessing crack initiation and propagation with considerable error, $14.5 \%$, provided by data assumed from the literature for this configuration.

\section{Acknowledgements}

The authors would like to thank the UK Ministry of Defence and Lloyd's Register EMEA for their continued support and without whom this research would not have been possible. The authors acknowledge the use of the IRIDIS High Performance Computing Facility, and associated support services at the University of Southampton, in the completion of this work.

\section{References}

[1] J. Yap. The analysis of skin-to-stiffener debonding in composite aerospace structures. Composite Structures, 57(1-4):425-435, jul 2002.

[2] J. F. M. Wiggenraad, R. Aoki, M. Gädke, E. Greenhalgh, D. Hachenberg, K. Wolf, and R. Bübl. Damage propagation in composite structural elements-analysis and experiments on structures. Composite structures, 36 (3-4):173-186, 1996.

[3] C. Meeks, E. Greenhalgh, and B. Falzon. Stiffener debonding mechanisms in post-buckled CFRP aerospace panels. Composites Part A: Applied Science and Manufacturing, 36(7):934-946, jul 2005.

[4] A. C. Orifici, I. Dezaratealberdi, R. Thomson, and J. Bayandor. Compression and post-buckling damage growth and collapse analysis of flat composite stiffened panels. Composites Science and Technology, 68(15-16): 3150-3160, dec 2008.

[5] S. Suh. Compression behavior of stitched stiffened panel with a clearly visible stiffener impact damage. Composite Structures, 62(2):213-221, nov 2003.

[6] J. E. Yetman, A. J. Sobey, J. I. R. Blake, and R. A. Shenoi. Investigation into skin stiffener debonding of top-hat stiffened composite structures. Composite Structures, 132:1168-1181, 2015.

[7] J. Yetman, A. Sobey, J. Blake, and R. Shenoi. Mechanical and fracture properties of glass vinylester interfaces. Composites Part B: Engineering, vol. 130:pp. 38-45, 2017. 
[8] D. Dugdale. Yielding of steel sheets containing slits. Journal of the Mechanics and Physics of Solids, 8(2):100-104, may 1960.

[9] A. Turon, C. Dávila, P. P. Camanho, and J. Costa. An engineering solution for mesh size effects in the simulation of delamination using cohesive zone models. Engineering Fracture Mechanics, 74(10):1665-1682, jul 2007.

[10] G. Alfano and M. A. Crisfield. Finite element interface models for the delamination analysis of laminated composites: mechanical and computational issues. International Journal for Numerical, (March 2000):17011736, 2001.

[11] M. Benzeggagh and M. Kenane. Measurement of mixed-mode delamination fracture toughness of unidirectional glass/epoxy composites with mixedmode bending apparatus. Composites Science and Technology, 56(4):439449, 1996.

[12] F. Dharmawan, G. Simpson, I. Herszberg, and S. John. Mixed mode fracture toughness of GFRP composites. Composite Structures, 75(1-4):328338, sep 2006.

[13] K. N. Shivakumar. Carbon/Vinyl Ester Composites for Enhanced Performance in Marine Applications. Journal of Reinforced Plastics and Composites, 25(10):1101-1116, may 2006. 


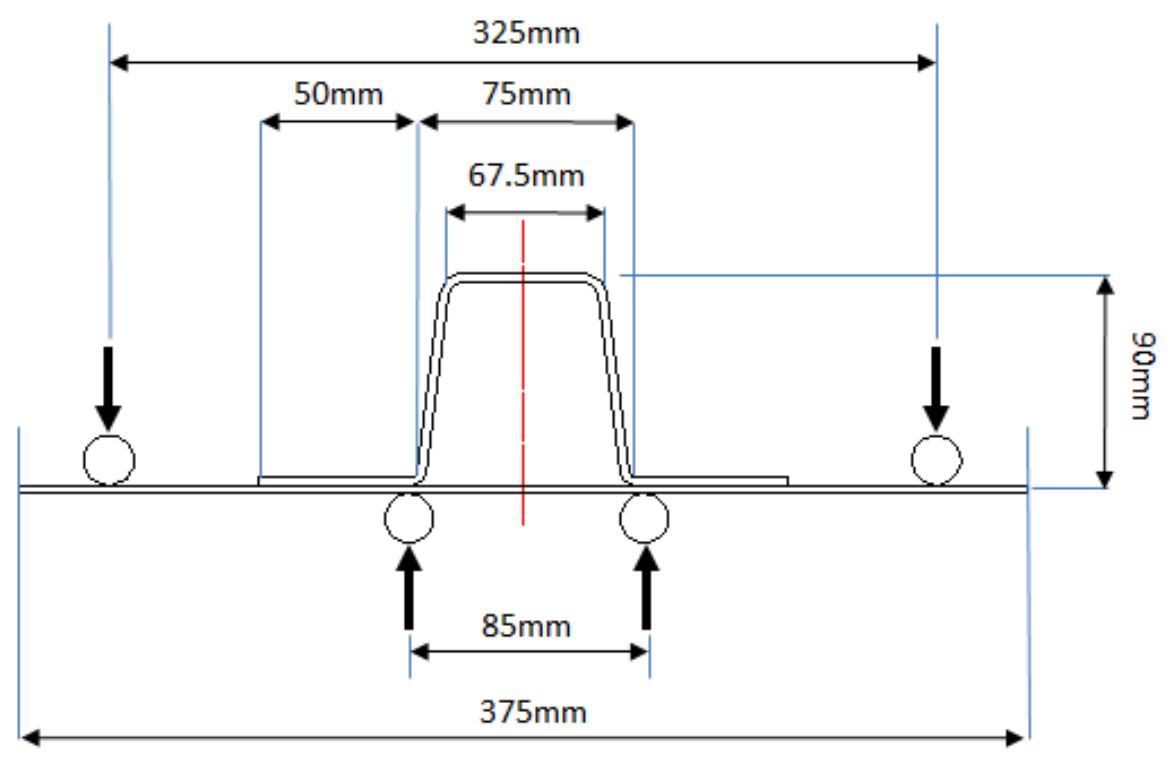

Figure 1: Four Point Bend Test Configuration

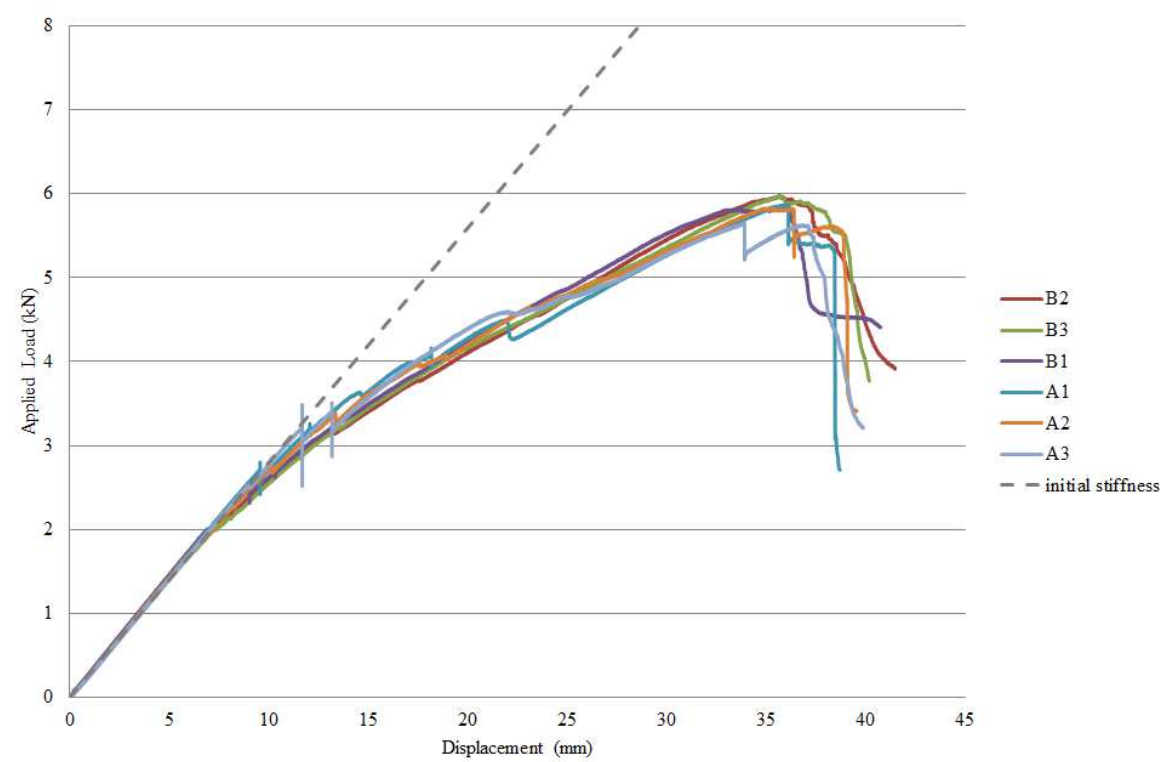

Figure 2: Four Point Bend: Test Data Load Displacement Curve for Stiffenera A and B 


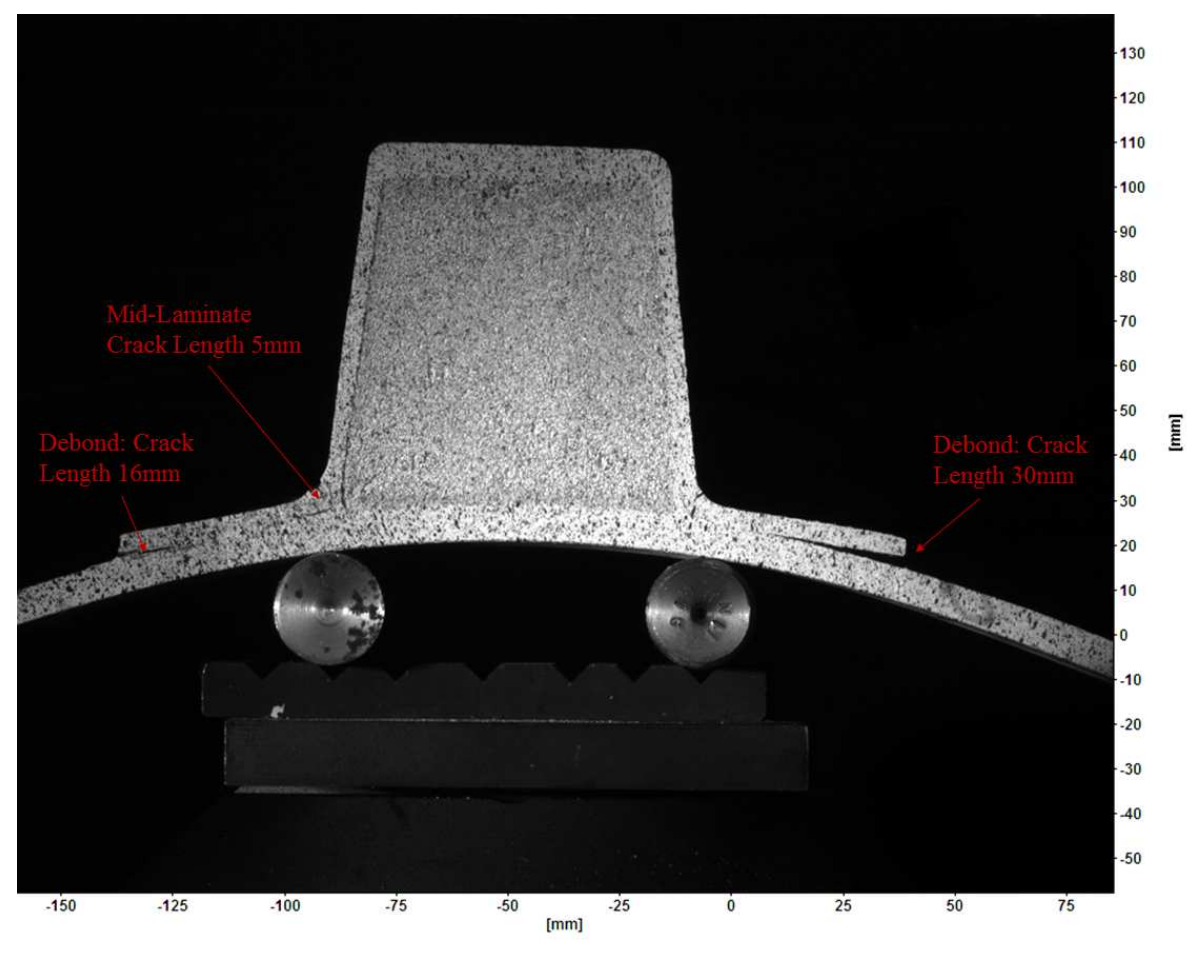

Figure 3: Four Point Bend: Test A3 at 35.6mm Displacement 


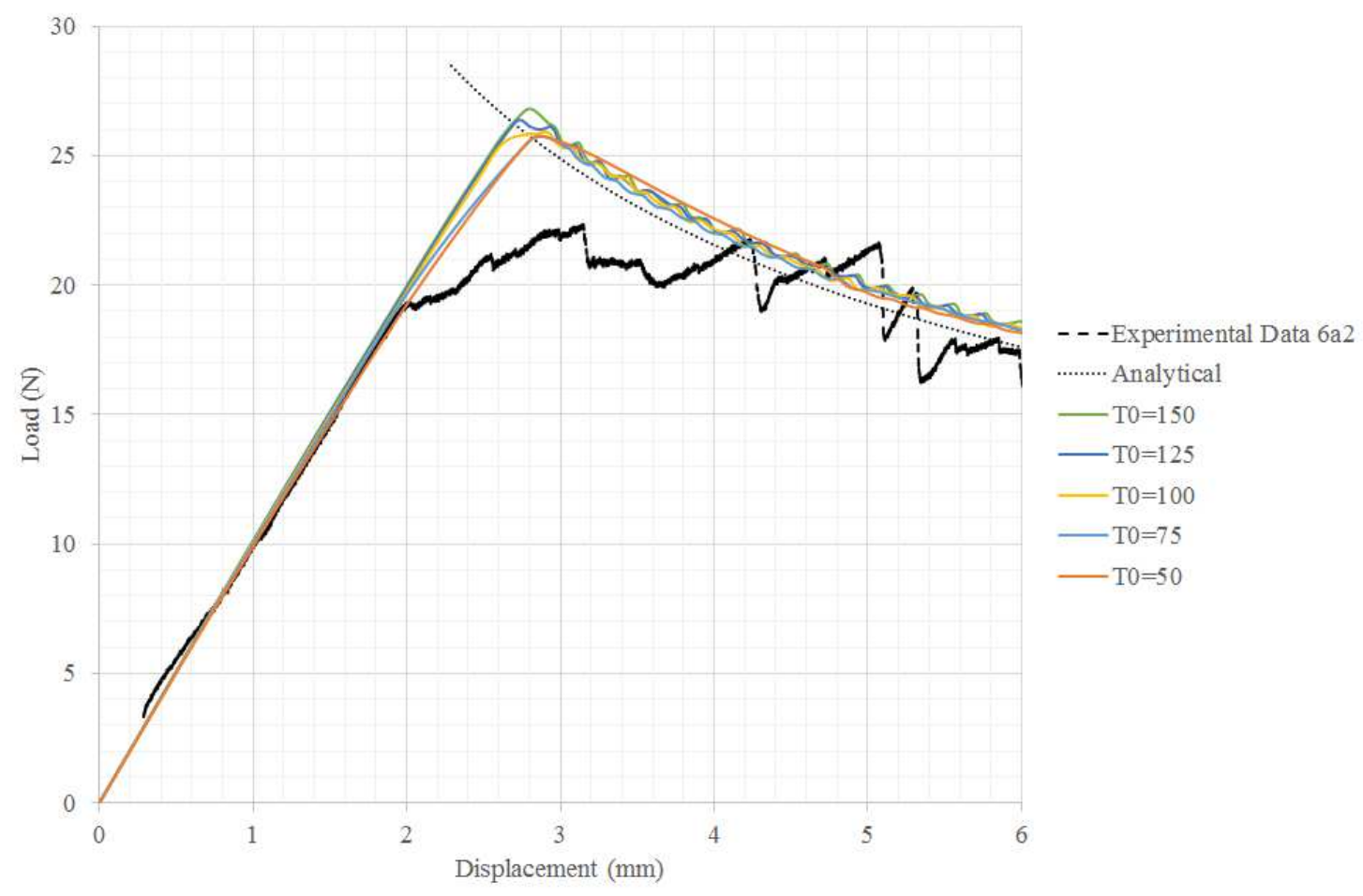

Figure 4: Double Cantilever Beam; Load Displacement Curve for Varying Interface Strengths

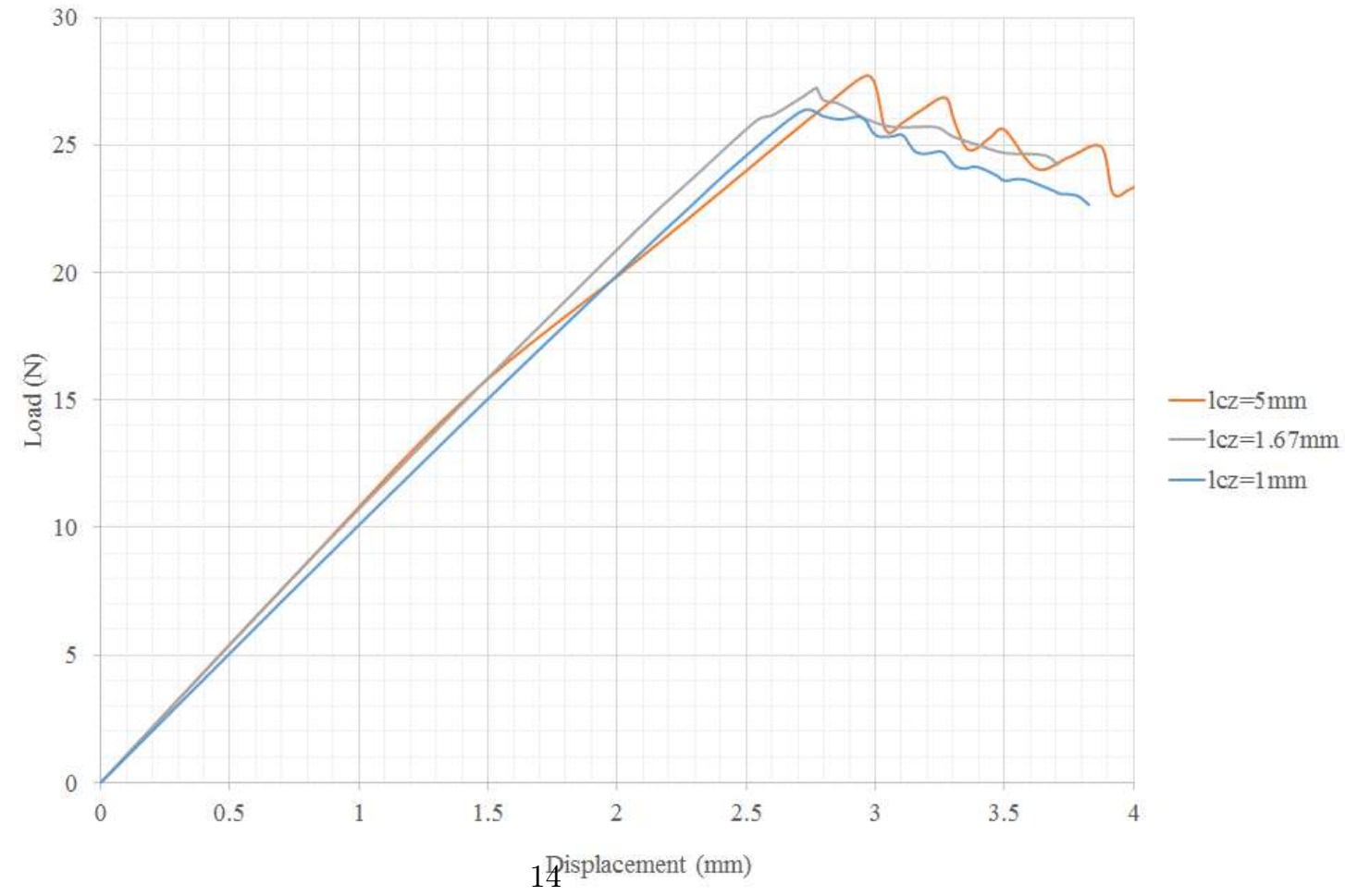

Figure 5: Double Cantilever Beam; Load Displacement Curve for Artificial Cohesive Zone Lengths 


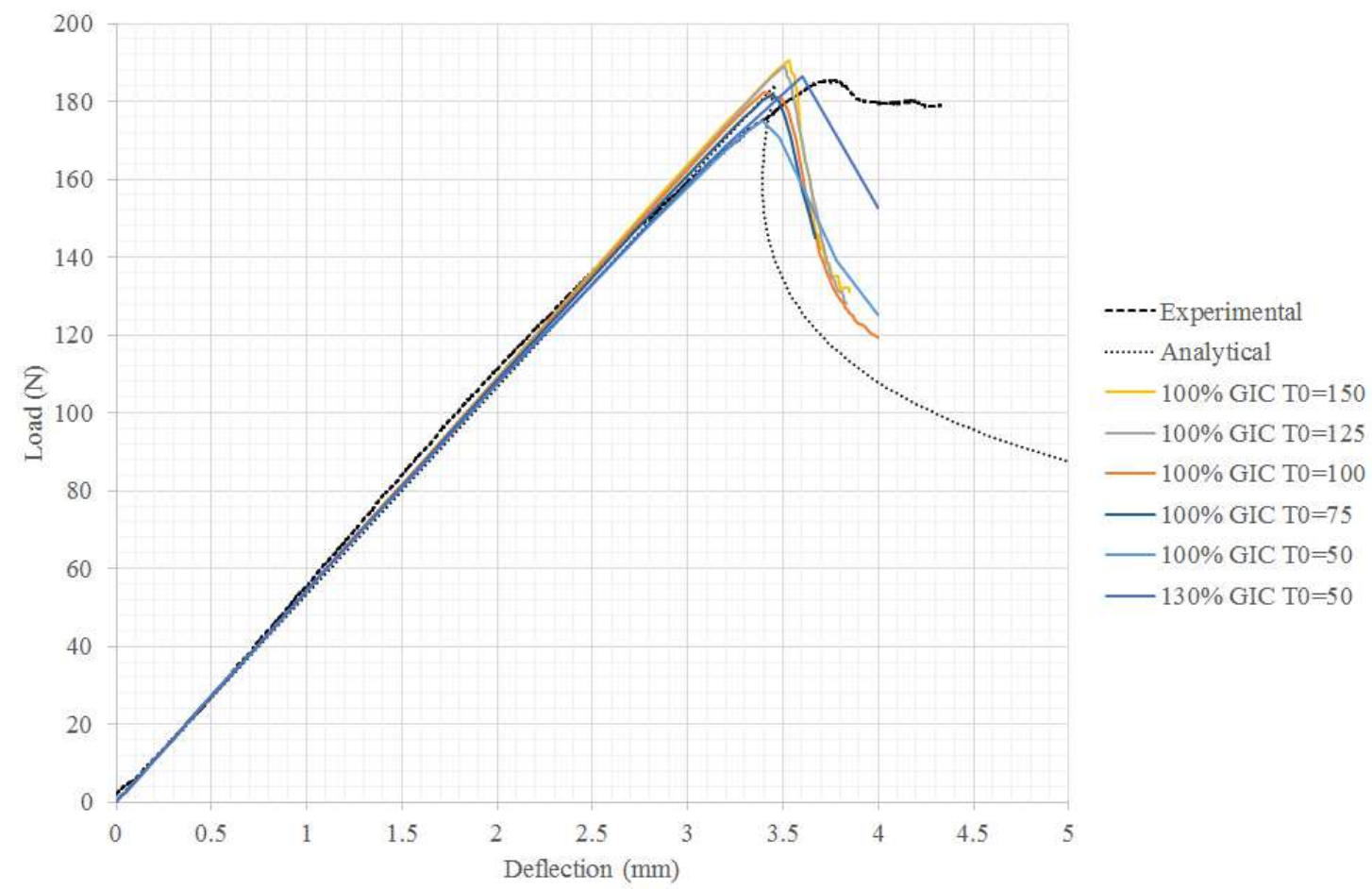

Figure 6: End Notch Failure; Load Displacement Curve for Varying Interface Strengths

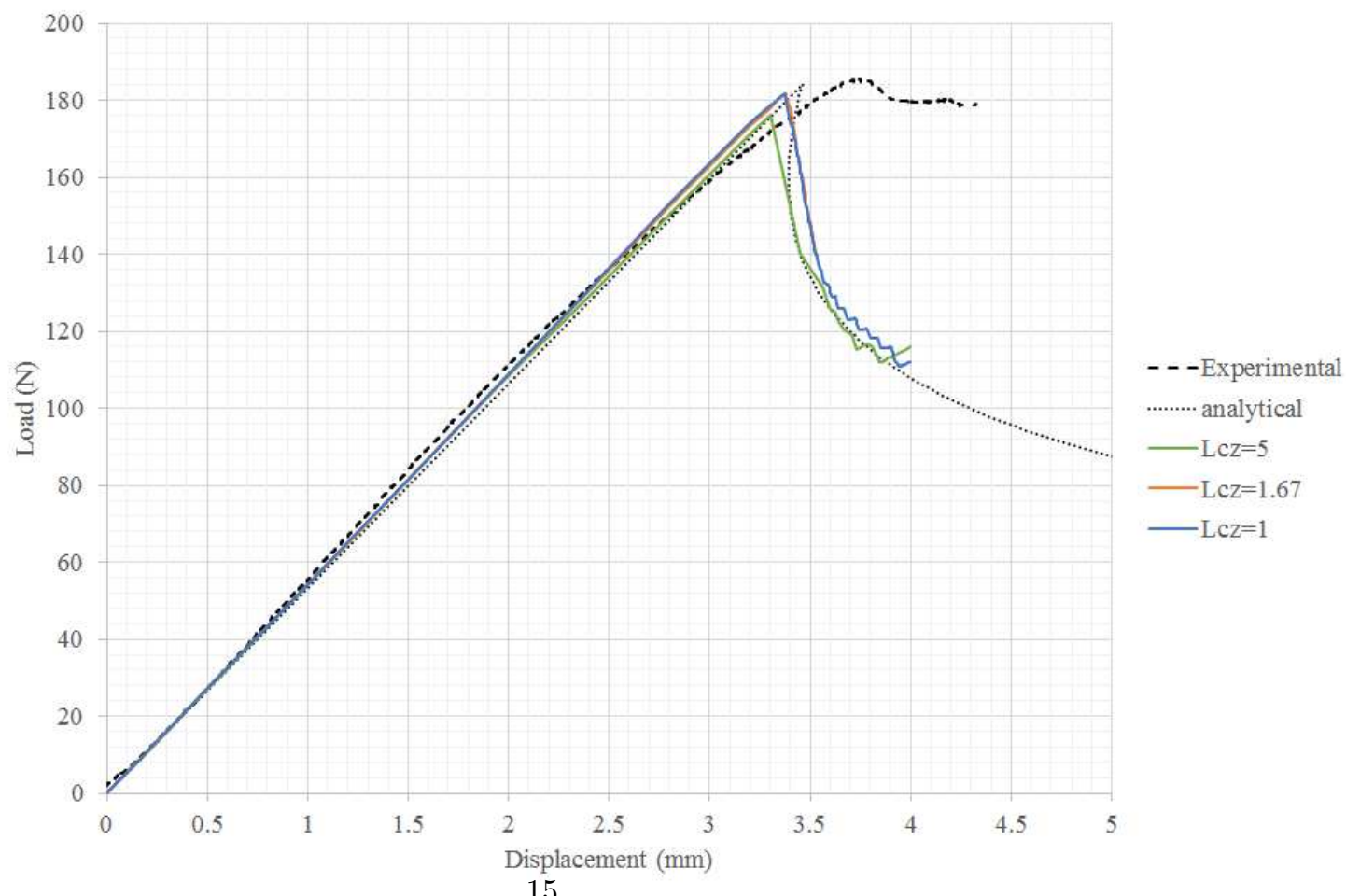

Figure 7: End Notch Failure; Load Displacement Curve for Artificial Cohesive Zone Lengths 


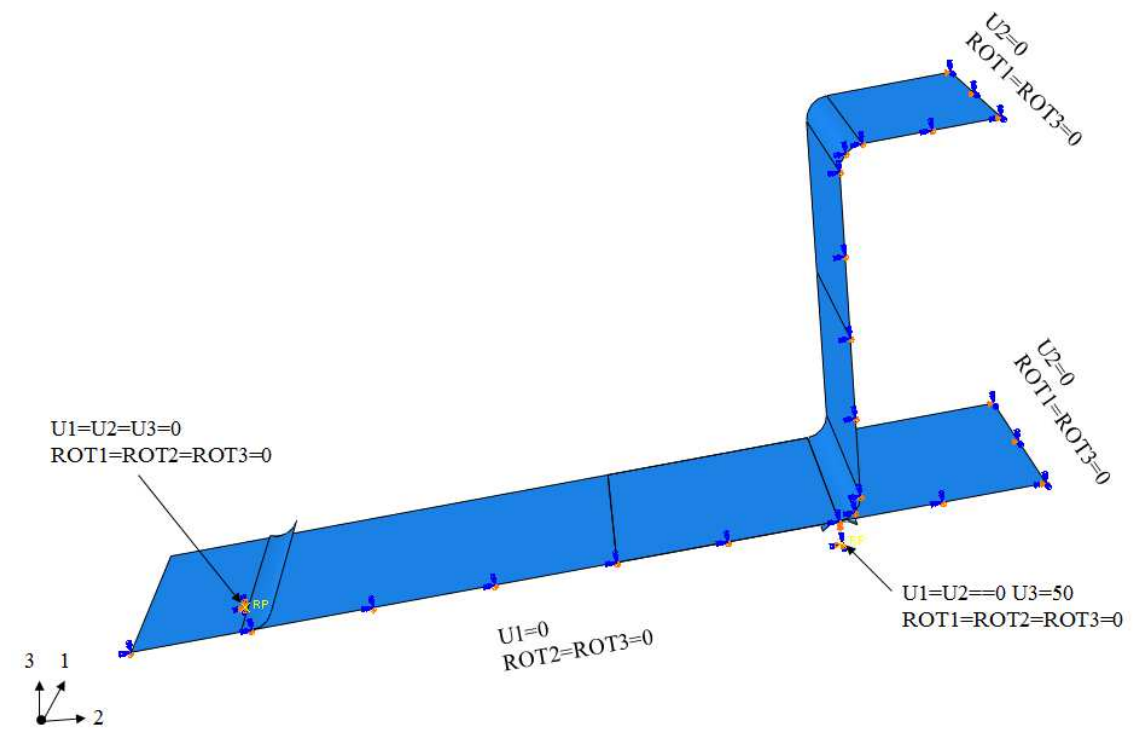

Figure 8: Four Point Bend: FEA Model Set-up

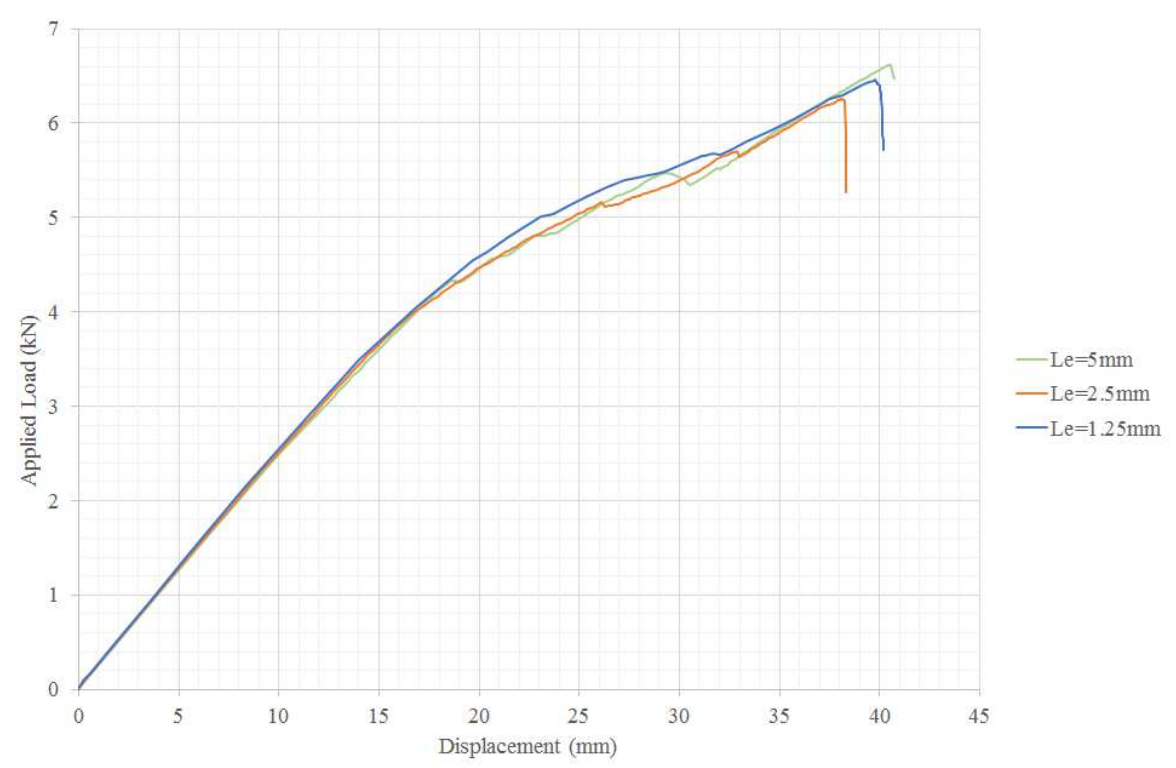

Figure 9: Four Point Bend: Mesh Convergence 


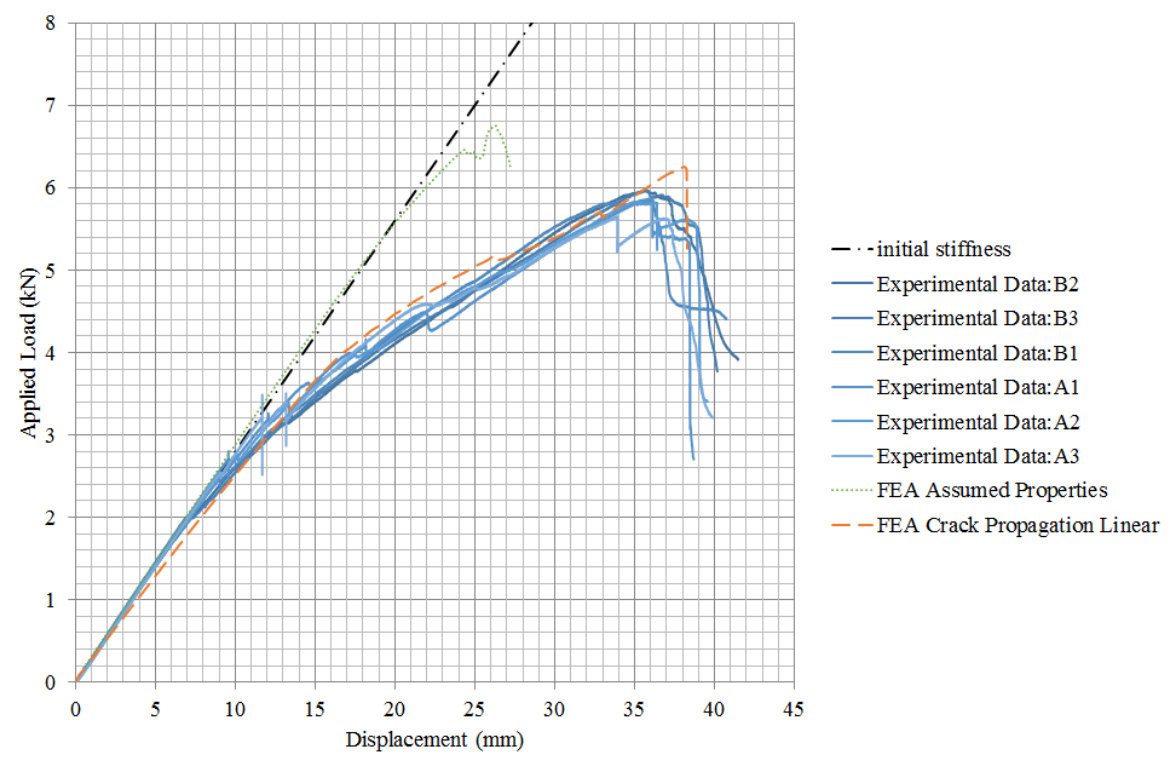

Figure 10: Four Point Bend: Comparison of Model

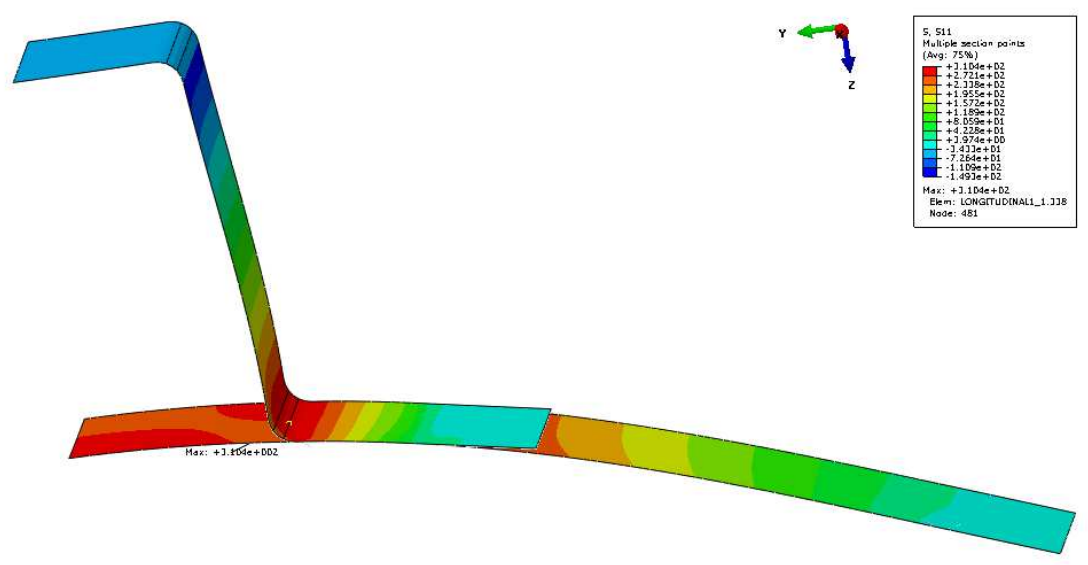

Figure 11: Four Point Bend: Stress Plot at $47.5 \mathrm{~mm}$ roller displacement 
Table 1: Observations for Panel A3 During Four Point Bend Test

\begin{tabular}{|c|c|c|}
\hline $\begin{array}{c}\text { Roller } \\
\text { Displacement }\end{array}$ & $\begin{array}{c}\text { Left Side } \\
\text { Observations }\end{array}$ & $\begin{array}{c}\text { Right Side } \\
\text { Observations }\end{array}$ \\
\hline $6.3 \mathrm{~mm}$ & \multicolumn{2}{|c|}{ audible cracking } \\
\hline $6.4 \mathrm{~mm}$ & & $\begin{array}{c}\text { crack visible on the right } \\
\text { outer flange edge }\end{array}$ \\
\hline $8.8 \mathrm{~mm}$ & & $\begin{array}{c}9 \mathrm{~mm} \text { crack on the right } \\
\text { outer flange edge }\end{array}$ \\
\hline $9.24 \mathrm{~mm}$ & & $\begin{array}{c}15 \mathrm{~mm} \text { crack on the right } \\
\text { outer flange edge }\end{array}$ \\
\hline $19.7 \mathrm{~mm}$ & $\begin{array}{l}\text { Small Crack initiates at } \\
\text { left inner curve }\end{array}$ & \\
\hline $22.5 \mathrm{~mm}$ & $\begin{array}{c}\text { crack visible on the left } \\
\text { outer flange edge }\end{array}$ & \\
\hline $24.5 \mathrm{~mm}$ & $5 \mathrm{~mm}$ crack at inner curve & \\
\hline $27.0 \mathrm{~mm}$ & $\begin{array}{c}\text { gradual debond of left } \\
\text { flange edge }\end{array}$ & $\begin{array}{c}\text { gradual debond of right } \\
\text { flange edge }\end{array}$ \\
\hline $28.8 \mathrm{~mm}$ & $\begin{array}{c}16 \mathrm{~mm} \text { crack on the left } \\
\text { outer flange edge }\end{array}$ & \\
\hline $35.6 \mathrm{~mm}$ & $\begin{array}{r}\text { significant damage } \\
\text { in contac }\end{array}$ & $\begin{array}{l}\text { opagation on plate } \\
\text { ith roller }\end{array}$ \\
\hline
\end{tabular}

Table 2: Observations for Panel B3 During Four Point Bend Test

\begin{tabular}{|c|c|c|}
\hline $\begin{array}{c}\text { Roller } \\
\text { Displacement }\end{array}$ & $\begin{array}{c}\text { Left Side } \\
\text { Observations }\end{array}$ & $\begin{array}{c}\text { Right Side } \\
\text { Observations }\end{array}$ \\
\hline $7.1 \mathrm{~mm}$ & \multicolumn{2}{|c|}{ audible cracking } \\
\hline $9.5 \mathrm{~mm}$ & $\begin{array}{c}\text { crack initiates at inner } \\
\text { curve }\end{array}$ & \\
\hline $15.5 \mathrm{~mm}$ & $\begin{array}{l}\text { crack visible on the left } \\
\text { inner flange edge }\end{array}$ & \\
\hline $15.9 \mathrm{~mm}$ & & $\begin{array}{c}\text { crack visible on the inner } \\
\text { curve }\end{array}$ \\
\hline $19.5 \mathrm{~mm}$ & & $\begin{array}{l}\text { crack visible on the right } \\
\text { outer flange edge }\end{array}$ \\
\hline $20.4 \mathrm{~mm}$ & $\begin{array}{l}\text { crack visible on the left } \\
\text { outer flange edge }\end{array}$ & \\
\hline $28.8 \mathrm{~mm}$ & $\begin{array}{l}\text { crack growth to } 5 \mathrm{~mm} \text { on } \\
\text { the left outer flange edge }\end{array}$ & $\begin{array}{c}\text { crack growth to } 12 \mathrm{~mm} \text { on } \\
\text { the right outer flange } \\
\text { edge }\end{array}$ \\
\hline $32.9 \mathrm{~mm}$ & $\begin{array}{r}\text { significant damage } \\
\text { in contac }\end{array}$ & $\begin{array}{l}\text { opagation on plate } \\
\text { vith roller }\end{array}$ \\
\hline
\end{tabular}


Table 3: Double Cantilever Beam: Interface Strength (MPa) for Increasing Cohesive Zone Length

\begin{tabular}{|c|c|c|c|}
\hline & $1.0 \mathrm{~mm}$ & $1.67 \mathrm{~mm}$ & $5.0 \mathrm{~mm}$ \\
\hline$t_{o_{I}}$ & 113 & 88 & 51 \\
\hline$t_{o_{I I}}$ & 150 & 116 & 67 \\
\hline
\end{tabular}

Table 4: Interface Parameters for DCB and ENF Samples

\begin{tabular}{|c|c|c|}
\hline & Mode I & Mode II \\
\hline Cohesive Zone Length, $l_{c z},(\mathrm{~mm})$ & 0.82 & 1.00 \\
\hline Interface Strength, $t_{o_{i}},(\mathrm{MPa})$ & 125 & 150 \\
\hline Interface Parameter, $\mathrm{M}$ & 0.45 & 0.57 \\
\hline Critical Strain Energy Release Rate, $G_{i} k J / m^{2}$ & 1.15 & 1.59 \\
\hline
\end{tabular}


Table 5: Material Properties

\begin{tabular}{|c|c|c|c|}
\hline Property & $\begin{array}{c}\text { WRE580 } \\
\text { Assumed } \\
\text { Properties }\end{array}$ & UE500 & $\begin{array}{c}\text { WRE580 } \\
\text { Experimental } \\
\text { Results }\end{array}$ \\
\hline $\begin{array}{c}\text { Tensile Young's } \\
\text { Modulus, } E_{11 T}(\mathrm{MPa})\end{array}$ & $26550(1)$ & $26790(3)$ & $22100(4)$ \\
\hline $\begin{array}{c}\text { Tensile Young's } \\
\text { Modulus, } E_{22 T}(\mathrm{MPa})\end{array}$ & $26550(1)$ & $5850(3)$ & $22100(4)$ \\
\hline $\begin{array}{c}\text { Tensile Young's } \\
\text { Modulus, } E_{33 T}(\mathrm{MPa})\end{array}$ & $2655^{*}$ & $5850(3)$ & $2200^{*}$ \\
\hline $\begin{array}{c}\text { Compressive Young's } \\
\text { Modulus, } E_{11 C}(\mathrm{MPa})\end{array}$ & $29400(1)$ & $26790(3)$ & $31200(4)$ \\
\hline $\begin{array}{c}\text { Compressive Young's } \\
\text { Modulus, } E_{22 C}(\mathrm{MPa})\end{array}$ & $29400(1)$ & $5850(3)$ & $31200(4)$ \\
\hline $\begin{array}{c}\text { Compressive Young's } \\
\text { Modulus, } E_{33 C}(\mathrm{MPa})\end{array}$ & $2940^{*}$ & $5850(3)$ & $3400^{*}$ \\
\hline $\begin{array}{c}\text { Shear Modulus, } G_{12} \\
(M P a)\end{array}$ & $4400(1)$ & $2200(3)$ & $7000(4)$ \\
\hline $\begin{array}{c}\text { Shear Modulus, } G_{13} \\
(M P a)\end{array}$ & $4400^{*}$ & $2200(3)$ & $7000^{*}$ \\
\hline $\begin{array}{c}\text { Shear Modulus, } G_{23} \\
(M P a)\end{array}$ & $4400^{*}$ & $2200(3)$ & $7000^{*}$ \\
\hline $\begin{array}{c}\text { Bonzeggagh-Kenane } \\
\text { exponent, } \eta_{B K}\end{array}$ & $1.17(2)$ & - & $1.59(4)$ \\
\hline $\begin{array}{c}\text { Moisson's Ratio, } \nu_{12} \\
\text { SERR, } G_{I C}\left(k J / m^{2}\right)\end{array}$ & $0.16(1)$ & $0.272(3)$ & $0.154(4)$ \\
\hline $\begin{array}{c}\text { Mode II Critical } \\
\text { Sensile Strength, } S_{22 T} \\
(\mathrm{MPa})\end{array}$ & $431(1)$ & $17.6(3)$ & $0.154^{*}$ \\
\hline $\begin{array}{c}\text { Poisson's Ratio, } \nu_{13} \\
S_{11 C}(\mathrm{MPa})\end{array}$ & $0.408^{*}$ & $0.058(3)$ & $0.154^{*}$ \\
\hline Poisson's Ratio, $\nu_{23}$ & $0.408^{*}$ & $0.058(3)$ & $444^{*}$ \\
\hline $\begin{array}{c}\text { Tensile Strength, } S_{11 T} \\
(\mathrm{MPa})\end{array}$ & $431^{*}$ & $482.0(3)$ & $272(4)$ \\
\hline $\begin{array}{c}\text { Shear Strength, } S_{12} \\
\text { Compressive Strength, }\end{array}$ & $350(1)$ & $308.0(3)$ & $57(4)$ \\
\hline
\end{tabular}

(*) assumed or calculated properties.

(1) Averaged from Shivakumar [13] tested E-glass woven roving with a Dow Derakane 510A-40 brominated vinyl ester manufactured via VARTM

(2) Dharmawan et al. [12] tested 800gsm woven E glass with a Derakane 411-350 matrix, data averaged if from multiple sources.

(3) Manufacturer's Data 20

(4) Yetman et al. [7] tested 600gsm woven E glass with aScott Bader Crystic Resin VE679-03PA. 